\title{
VERBALIZACIÓN DE EMOCIONES COMO HERRAMIENTA DE LA CORTESÍA EN EL ESPAÑOL PENINSULAR
}

\author{
OLENA KURCHENKO \\ Universidad Nacional Tarás Shevchenko de Kíev, Ucrania
}

\begin{abstract}
Resumen. El desarrollo de la emotiología como un nuevo ámbito de estudio interdisciplinar a caballo entre la lingüística y la psicología, junto con los descubrimientos revolucionarios en la investigación de las emociones gracias a la ciencia neuronal, permiten un nuevo enfoque de la verbalización (y de la nominación) de las emociones en el contexto de la cortesía (y la descortesía) en muchas lenguas, incluido el español peninsular. El objetivo del presente artículo es aplicar la teoría de emociones construidas de Feldman Barret al estudio de la verbalización de emociones por la parte de los participantes del concurso culinario Masterchef 6 (2018), Masterchef Celebrity 3 (2018), Masterchef Junior 6 (2018) en TVE con el fin de analizar las estrategias de cortesía.
\end{abstract}

Palabras clave: cortesía verbal, emotiología, pragmática sociocultural, ciencias afectivas, realismo afectivo

\section{INTRODUCCIÓN}

La lingüística empezó a interesarse por las emociones en los años 70-80 del siglo pasado, y una de las afirmaciones compartidas por los lingüistas de entonces era que los nombres de las emociones no son recursos emotivos, algo que no puede estar más lejos de la realidad, y que ahora mismo se está enfocando desde un punto de vista totalmente opuesto. Ya hace más de 15 años el emotiólogo ruso Shajóvskiy afirmaba que los nombres de las emociones sí pertenecen a los recursos emotivos léxicos (Shajovskiy, 2009: 25).

Hoy en día esas intuiciones se confirman gracias a los recientes logros de la neurociencia, en particular, a la teoría de las emociones construidas de Lisa Feldman Barrett. Tras 20 años de investigaciones, la directora del Laboratorio de Ciencias Afectivas Interdisciplinarias de la Universidad de Northeastern afirma que la verbalización de las emociones juega el papel principal en su correcta comunicación.

Hasta ahora la emotiología lingüística nunca había tenido contacto alguno con la neurociencia por la razón evidente de que los logros de la neurociencia en el 
ámbito de las emociones son muy recientes. De hecho, el libro de Feldman Barrett sobre la teoría de las emociones construidas How Emotions are Made: The Secret Life of the Brain fue publicado por primera vez en 2017, y ya al cabo de un año fue traducido a muchas lenguas (incluido el español La vida secreta del cerebro: Cómo se construyen las emociones) llegando a ser un indiscutible bestseller mundial. En palabras de la propia Feldman Barrett:

Poco a poco, la ciencia de la mente está prescindiendo, por fin, de sus "ruedines" auxiliares. El cráneo ya no es el campo de fuerza que fue antaño, ahora que la tecnología de la imaginología cerebral puede observar de manera inocua el interior de la cabeza humana. Nuevos dispositivos portátiles de medición trasladan la psicología y la neurociencia del laboratorio al mundo real. (Feldman Barrett, 2018: 349-350)

\section{EL CONCEPTO DE CORTESÍA Y LAS EMOCIONES}

El objeto de nuestra investigación es el estudio de la verbalización de emociones utilizada como elemento de estrategias de cortesía, con el fin de establecer y mantener relaciones armoniosas entre los interlocutores. Como material nos valemos del ciclo de programas del concurso culinario Masterchef 6 (2018), Masterchef Celebrity 3 (2018), Masterchef Junior 6 (2018) en TVE. Nuestra elección se explica por la diversidad de situaciones que viven los concursantes tanto en grupo como individualmente por la espontaneidad de sus actos de habla, así como por la expresión tan viva de dos (tan importantes en la teoría de la cortesía de Brown y Levinson) aspiraciones de cada uno: la de afiliación al grupo de concursantes y la de prosperar individualmente en el concurso y llegar a la victoria (Brown y Levinson, 1987: 15). La peculiaridad del material elegido consiste en la diversidad de los hablantes: los concursantes del Masterchef clásico son gente de procedencia muy variada, de diferentes edades y profesiones, y los une el hecho de ser aficionados a la cocina; de los participantes de Masterchef Junior se puede decir lo mismo, pero además todos ellos son niños (de 7 a 12 años); en Masterchef Celebrity, en cambio, los concursantes son famosos (deportistas, actores, cantantes, modelos, directores, escritores etc.) a los que les gusta pasar tiempo en la cocina y que participan con ganas en el programa.

Por ser la estrategia principal de mantener las relaciones armoniosas (o sea el equilibrio emocional) entre las personas, la cortesía es vital en nuestra comunicación cotidiana.

De las diversas definiciones que se han dado de la cortesía, una de las que nos parecen más acertadas es la que Escandell recoge en su libro Introducción a la pragmática:

La cortesía puede entenderse de dos maneras diferentes. Puede concebirse, en primer lugar, como un conjunto de normas sociales, establecidas por cada sociedad, que regulan el comportamiento 
adecuado de sus miembros, prohibiendo algunas formas de conducta y favoreciendo otras: lo que se ajusta a las normas se considera cortés, y lo que no se ajusta es sancionado como descortés. Esta cortesía se ha interpretado como un mecanismo de salvaguardia que establecen todas las sociedades para que la agresividad de sus miembros no se vuelva contra ellos mismos. (Escandell, 1996: 136)

Por otra parte, Yus, en la obra Ciberpragmática. El uso del lenguaje en Internet, trata este tema así: 'La cortesía es una estrategia típicamente humana destinada a favorecer las relaciones entre los semejantes y mitigar la imposición de determinadas acciones a otras personas' (Yus, 2001: 187).

Nos parece oportuno basarnos en los recientes logros de la neurociencia, y en concreto, en la teoría de las emociones construidas de Lisa Feldman Barrett que une ideas de varias tendencias de estudios de construcción de las emociones: de la construcción social Feldman Barrett ha tomado la idea de la importancia de la influencia de la cultura y de la visión del mundo; de la construcción psicológica, el postulado de que las emociones se construyen por los sistemas básicos del cerebro y del cuerpo; y de la construcción neuronal, la conclusión sobre el hecho de que la experiencia crea sinapsis en el cerebro:

las interconexiones de nuestro cerebro no son consecuencias inevitables solo de nuestros genes. Hoy sabemos que la experiencia es un factor que también contribuye. Los genes, incluyendo los que conforman el "cableado" del cerebro, se activan y se desactivan en contextos diferentes (los científicos llaman a este fenómeno plasticidad). Esto significa que algunas de nuestras sinapsis se han creado literalmente porque otras personas nos han hablado o nos han tratado de una manera determinada. En otras palabras, la construcción se extiende hasta el nivel celular. La estructura "macro" de nuestro cerebro en gran medida viene predeterminada, pero el "microcableado" no. En consecuencia, las experiencias pasadas contribuyen a determinar nuestras experiencias y percepciones futuras. (Feldman Barrett, 2018: 58)

Uno de los conceptos básicos introducidos por Feldman Barrett en los marcos de la teoría de las emociones construidas es el concepto del realismo afectivo. Este concepto nos ayudará a comprender por qué la percepción de lo dicho puede ser tan variable dependiendo de quién, dónde y en qué situación lo 'decodifica'.

Cuando experimentamos un afecto sin saber la causa, es más probable que tratemos ese afecto como información sobre el mundo y no como nuestra experiencia del mundo. El psicólogo Gerald L. Clore se ha pasado decenios realizando experimentos ingeniosos para entender mejor cómo tomamos decisiones cada día basándonos en corazonadas. Este fenómeno se llama realismo afectivo porque experimentamos unos hechos supuestos sobre el mundo que en parte son creados por nuestras sensaciones (Feldman Barrett, 2018: 105). 


\section{REALISMO AFECTIVO Y VERBALIZACIÓN DE EMOCIONES}

De tal manera, el realismo afectivo puede hacer que una persona en el momento de excitación febril dote una frase neutral de valor negativo, y por lo tanto pueda percibirla como ofensiva.

Para una mejor comprensión del concepto del realismo afectivo se usa el concepto de interocepción: la interpretación que da nuestro organismo a nuestro estado fisiológico. Feldman Barrett afirma que nuestro cerebro 'confunde' fácilmente nuestros índices fisiológicos con emociones: por ejemplo, a personas con taquicardia (por razones cardiológicas) las caracteriza una inclinación a alarmarse, porque el cerebro interpreta los latidos acelerados del corazón como 'alarma' (aunque la causa realmente es otra).

Del mismo modo las emociones son capaces de provocar las sensaciones fisiológicas típicas para ellas. Pongamos algunos ejemplos:

Josetxo (11 años), antes del anuncio de los puntos acumulados en el tercer día del concurso:

- Yo tengo un nudo en la tripa y en la garganta.

(Programa 3 Masterchef Junior 6, 00:40:50)

Dos niñas esperando el veredicto final de los jueces que va a definir si se quedan o dejan el concurso:

- Tenemos que estar tranquilas, tía, da igual...

- Me duele la tripa y todo.

(Programa 1 Masterchef Junior 6, 00:41:25)

Samantha comentando el estado emocional de Oxana que está presentando su plato al jurado, aquí vemos que describe los síntomas fisiológicos de nerviosismo de Oxana:

S: ¡Cómo te tiembla el pulso, eh, Oxana!

O: Estoy súper nerviosa...

(Programa 12 Masterchef 6, 00:35:07)

A continuación:

S: Estas lágrimas que has soltado cuando veías que comíamos tu plato son el resultado de la pasión que tú le pones a tu cocina.

(Programa 12 Masterchef 6, 00:38:12)

Un niño de 10 años esperando el veredicto de los jueces:

Unai: ¡Me voy a desmayar!

(Programa 1 Masterchef Junior 6, 00:38:00)

En el siguiente ejemplo los niños podían elegir de qué capitán desean ir, y nadie quiere ir al equipo del capitán Dani: 
Niños: ¡Dani, no llores!

Dani: No lloro, pero estoy a punto. Pero aún no lloro. Aún no.

(Programa 3 Masterchef Junior 6, 00:48:54)

El mismo Dani en otro concurso de repente se sintió mal:

Dani: Estoy sofocado. Es que no puedo, tío, estoy sofocado, me tengo que sentar. Entre el calor y las patatas que ya no me salen... ya no sé ni hablar.

Paula: Dani, ¿qué te pasa?

Dani: Estoy nervioso. Cuando estoy nervioso, me sofoco que significa que como no pare, me explota la cabeza.

(Programa 4, Masterchef Junior 6, 00:01:14)

Evelyn (12 años) y Ferrán (10 años) vuelven al concurso después de la repesca:

Evelyn: Volver a las cocinas Masterchef es una experiencia superguay y siento como un hormigueo por todo el cuerpo.

Ferrán: A mí me ha llenado de magia el cuerpo y es una experiencia muy guay.

(Programa 4, Masterchef Junior 6, 00:01:38)

En el siguiente ejemplo Samantha (una de los 3 jueces) está descontenta con el trabajo de los concursantes:

S: ¡Vaya desastre de postre! No os digo más. ¡Me muero de la rabia!

(Programa 1, Masterchef Celebrity 3, 00:02:15)

Dice Feldman Barrett que 'las personas utilizan el afecto como información, creando realismo afectivo, en toda su vida cotidiana' (Feldman Barrett, 2018: 105-106).

El cerebro humano está programado para esta ilusión llamada realismo afectivo, parcialmente porque la interocepción momentánea crea en nosotros cierto afecto que nosotros interpretamos como información sobre el mundo. A la gente le gusta decir que ver significa creer, pero el realismo afectivo demuestra lo contrario: creer significa ver (u oír).

La estructuración anatómica del cerebro humano hace que ninguna decisión ni acto puedan ser libres de interocepción ni del afecto, por más que la gente se engañe en cuanto a su racionalidad. Las sensaciones de nuestros cuerpos ahora mismo proyectan de antemano lo que vamos a sentir y hacer en el futuro.

\section{EL CONCEPTO DE RESONANCIA EMOCIONAL Y LA CORTESIA}

Una de las funciones primordiales de las emociones (que como hemos visto, no son otra cosa que conceptos) está relacionada con la capacidad de los conceptos 
de regular el presupuesto de nuestro cuerpo. Dependiendo de cómo categorizamos nuestro sudor o sofoco, nuestro presupuesto del cuerpo puede experimentar cambios diferentes. La categorización de inquietud puede causar una emisión moderada de cortisol (por ejemplo, para levantar los brazos); la categorización de miedo, una emisión de cortisol más alta (para poder escapar); la categorización de descanso no exige ningún cortisol adicional.

A menudo la gente (sobre todo los adultos, aunque no todos) es consciente de que cada uno de los que viven la misma situación, pueden vivirla emocionalmente a su manera. Esto se ilustra muy bien con el siguiente ejemplo del Programa 3 de Masterchef Celebrity 3. Cinco concursantes participan en la prueba de eliminación (el que haga el peor plato queda eliminado). Cada uno de ellos tenía derecho de pedir ayuda a sus compañeros que ya han pasado a la siguiente etapa del concurso y están en la galería, que les ayuden y cocinen con ellos. A cuatro concursantes los compañeros les dijeron que sí, y a Antonia, la única compañera que quedaba en la galería, Carmen, le negó la ayuda (porque las relaciones entre ellas no eran especialmente buenas). De este modo, Antonia era la única quien hacía la tarea sola, y se sentía sola y abandonada, y más aún por haber pisado su propio orgullo y haber pedido ayuda a Carmen. Las siguientes réplicas tienen lugar después de la evaluación por el jurado del plato de Antonia, que no puede reprimir las lágrimas:

00:02:32 A: Las relaciones para mí son muy importantes y cada uno con su conciencia y ya está.

00:02:33 C (a sus compañeros en la galería): Yo, yo, yo, y todos los demás, nuestros enemigos.

María: Ella lo piensa así. Es que su realidad es otra y está equivocada.

(Programa 3. Masterchef Celebrity 3)

Luego, cuando de acuerdo con el veredicto final de los jueces, Antonia y Jaime tienen que dejar el programa, en la última entrevista con la presentadora Eva, continúa la discusión sobre las relaciones de Antonia con el resto de los concursantes que lo ven, oyen y responden desde la galería. El fragmento citado abajo confirma la siguiente afirmación de Feldman Barrett en cuanto al realismo afectivo: 'El afecto nos hace creer que los objetos y las personas del mundo son intrínsecamente negativas o positivas' (Feldman Barrett, 2018: 105).

00:02:41 E: Antonia, Jaime, es la primera vez que hay una doble expulsión y desde luego yo estoy completamente en shock, no sé, vosotros, ¿cómo os sentís, Antonia?

00:02:42 A: Este llanto para mí ha sido como de liberación. Me he liberado. Estoy bien [...] Pero mi llorar ha sido contra los fariseos.

Boris (balcón): ¡iFariseos?!

A: ¡Fariseos!

(Programa 3. Masterchef Celebrity 3) 
Luego vemos el desacuerdo total y general con Antonia tanto de los concursantes que se quedan en el programa como de Jaime, que se va a la vez que Antonia, de acuerdo con el veredicto de los jueces, lo cual subraya la evidencia del hecho que Antonia es prisionera de su propio 'realismo afectivo'.

00:02:35 Boris: Antonia, ¡nooo! ¡No insistas en eso!

00:02:36 María: No tienes razón.

00:02:36 Paz: Que no, no, Antonia, no.

00:02:37 Mario: No puede ser.

00:02:38 Todos: No, no.

00:02:39 A: Alguno(s) me han atacado de vez en cuando injustamente.

00:02:40 Paz: Me da coraje que lo termine así.

00:02:41 Jaime: Yo creo que, Antonia, estás exagerando un poco.

[...] Antonia, yo creo que no... no lo estás enfocando bien.

(Programa 3. Masterchef Celebrity 3)

En defensa de Antonia hay que decir que 'nuestras percepciones son tan vivas e inmediatas que nos obligan a creer que experimentamos el mundo tal como es, cuando en realidad experimentamos un mundo construido por nosotros' (Feldman Barrett, 2018: 119).

Veamos ahora como Paz Vega (desde la galería) se dirige a Antonia con el objetivo de sacarla de su realismo afectivo y crear en ella la resonancia emocional con el resto de los concursantes. Para ello se vale de la verbalización de sus emociones y sentimientos:

00:02:43 Paz: A mí me gustaría decir una cosa, porque, Antonia, yo te adoro y te quiero y lo sabes. Me da mucha pena que en ese momento tuyo que es tu despedida no saques lo bueno que has vivido, porque hemos vivido cosas muy bonitas y muy buenas aquí, jsí!

(Programa 3. Masterchef Celebrity 3)

Antonia da la respuesta de la cual se hace claro que está de acuerdo con Paz y que ha 'pasado la página', o, valiéndonos de la terminología de Feldman Barrett, su interocepción ha cambiado (como ella misma dijo en el fragmento arriba, después de sus lágrimas 'se ha liberado'). En su respuesta a Paz ella pide dejarlo atrás. Hay que tener en cuenta que el español no es lengua materna de Antonia y aunque ha vivido casi 30 años en España sus expresiones no siempre son gramaticalmente correctas, sobre todo cuando está nerviosa:

00:02:44 Antonia: Sí, un poco más de alegría, tenemos (que) cortar, cortar (hace gesto como cortando con las tijeras). Todo atrás, mi amor, todo atrás (hace gesto con las dos manos como tirando cosas detrás de su espalda).

(Programa 3. MasterchefCelebrity 3) 
Como se puede ver, finalmente la armonía está alcanzada, cosa que es siempre el objetivo de la cortesía.

\section{CONCLUSIONES}

Gracias a los recientes logros de la ciencia neuronal, y en particular a la recientemente formulada teoría de las emociones construidas de Feldman Barrett resalta la importancia de la nominación de la emoción (tanto la propia como la del otro) para conseguir una resonancia emocional adecuada por parte del interlocutor. Esta resonancia no es otra cosa que la cortesía, ya que es una estrategia dirigida a establecer relaciones armoniosas entre los interlocutores y minimizar la presión sobre el interlocutor. Precisamente ese es el objetivo de la verbalización (y la nominación) de las emociones: conseguir el equilibrio emocional en las relaciones con el interlocutor. De esta manera se evidencia que la verbalización (incluida la nominación) de las emociones es una herramienta de la cortesía.

\section{REFERENCIAS BIBLIOGRÁFICAS}

Brown, P. y Levinson, S. (1987) Politeness. Some Universals in Language Use. Cambridge: Cambridge University Press.

Escandell, M. V. (1996) Introducción a la pragmática. Barcelona: Ariel.

Feldman Barrett, L. (2018) La vida secreta del cerebro. Cómo se construyen las emociones. Barcelona: Paidós.

Shajovskiy, V. I. (2009) Yazyk i emotsii v aspekte lingvokulturologii. Volgograd: Izdatelstvo VGPU "Peremena".

Yus, F. (2001) Ciberpragmática. El uso del lenguaje en Internet. Barcelona: Ariel.

\section{RECURSOS DE ANÁLISIS EMPÍRICO}

Masterchef 6 (2018) Disponible en https://www.rtve.es/alacarta/videos/masterchef-6/ [Consultado el 20 de febrero de 2019].

Masterchef Celebrity 3 (2018) Disponible en https://www.rtve.es/television/masterchefcelebrity3/ [Consultado el 15 de febrero de 2019].

Masterchef Junior 6 (2018) Disponible en https://www.rtve.es/television/masterchef-junior-6/ [Consultado el 25 de febrero de 2019].

\section{VERBALIZATION OF EMOTIONS AS COURTESY TOOL IN PENINSULAR SPANISH}

Summary. The development of emotiology as an interdisciplinary new avenue of research between linguistics and psychology, together with the revolutionary discoveries in the investigation of emotions thanks to neuroscience, allow a new understanding of the verbalization of emotions in the context of politeness (and impoliteness) in many languages, including peninsular Spanish. The objective of this article is to apply Feldman Barret's theory of constructed emotions to the 
study of the verbalization of emotions by the participants of the culinary contest Masterchef 6 (2018), Masterchef Celebrity 3 (2018), Masterchef Junior 6 (2018) in TVE in order to analyze courtesy strategies.

Palabras clave: verbal politeness, emotiology, sociocultural pragmatics, affective sciences, affective realism

Olena Kurchenko (Dra. en Filología Románica, Profesora) trabaja actualmente en la Universidad Tarás Shevchenko de Kíev, Ucrania. Sus intereses académicos incluyen la pragmática sociocultural, la cortesía verbal, la emotiología y la comunicación intercultural. Correo electrónico: elena_2050@ukr.net 